\title{
Comparison of Malaysian and SAE J833 anthropometric proportions for vehicle package design
}

\author{
Zuli'zam Rashid $^{1, a}$, Nooh Abu Bakar ${ }^{1, b}$ and Raja Ariffin Raja Ghazilla ${ }^{2, c}$ \\ ${ }^{1}$ Faculty of Mechanical Engineering, Universiti Teknologi Malaysia, Skudai, Johor, Malaysia \\ ${ }^{2}$ Centre for Product Design and Manufacturing, Faculty of Engineering, University of Malaya, \\ 50603 Lembah Pantai, Kuala Lumpur, Malaysia \\ aZZLIZAR@proton.com, bnoohab@ic.utm.my, ${ }^{\mathrm{c}}$ __ariffin@um.edu.my
}

Keywords: Anthropometry, vehicle package, ratio, comparison

\begin{abstract}
Anthropometric measurements are critical dimensions when considering human interface design. This is especially true in vehicle package design where the interaction of the drive with the vehicle interior components need to be precisely determine as a mismatch between them would not only be detrimental to the drive's comfort but driving performance and safety as well. In the past car makers often depends on standard databases derived from population that are not necessarily suited to the local population. Among the key concerns are the anthropometric measurements values and body ratio which would drive the design requirements of the vehicle package. Thus this paper describes the study which has been done to understand Malaysian Anthropometry in comparison of current available databases. The results shows significant differences in body proportion which may lead to the necessity to further study the effect of this differences.
\end{abstract}

\section{Introduction}

The measurements of the human body, also known as anthropometry, are essential in the ergonomic design of products and workplaces. Since natural postures and movements are based on the dimensions of the torso, arms and legs, it is essential that the workplace should be suited to the body size of the operator. (Grandjean 1988). Herron (2001) defined anthropometry as the study of human body measurements which has a significant role in the construction of a functional humanmachine interface. The human machine interface can be categorized into three different parts; the human operator, the equipment (hardware and software) and the working environments (physical and psychosocial). The person performing the task would also vary because of the variations in physical features size, shape and strength.

There are several factors causing significant variations in human body sizes. The two main variations in body size between individuals are attributed to the gender and race of the person (Kianoush Fatollahzadeh, 2006). Hence, many countries have made the effort in establishing localized anthropometric databases for different population groups such as for civilian, military personnel, students and workers. ( Bolstad et al 2001, Wang et al 2002, MM Klarin et al., 2008, B.V.Shanasundara et al.,1999). In addition, ethnic diversity within a local population can also be a significant factor that may affect the anthropometric data and the scope of its application.( $\mathrm{Yu}-$ Cheng Li et al.,2004)

According to Pheasant (1996), the variations of body dimensions of different groups can be observed in terms of overall body size and bodily proportions. The means anthropometric dimensions, for example stature and sitting heights, are the most typical distinctions among ethnic groups. Another significant ethnic difference is in the bodily proportions, which are the ratios of body dimensions. Bodily proportion is a scaling relation obtained from the calculated ratio of one body dimension to a specific reference dimension. (Yu Cheng Li et al 2004) 
The study by $\mathrm{Yu}$ Cheng et al. (2004) has found that there are significant differences in means body dimensions and bodily proportions of the people in East-Asia, such as the Japanese, Chinese, Korean and Taiwanese, even though they are from the same region. For example, the Chinese tend to have narrow torso with moderate limbs while the Japanese have a wider torso and shorter limbs. The Korean have a moderate body shape within the group but the upper limbs are longer than the rest. The Taiwanese have wide shoulders and narrow hips with large hands and long legs.

In vehicle package design, vehicle designers would often refer to the SAE (Society of Automotive Engineers) Standards, which is based on a two-dimensional accommodation tools to design various vehicle components. The Standards includes details of the human dimensions or anthropometry, seating positions, reach envelopes, head contours and eye ellipse (Roe,1993). Examples of SAE Standard are SAE J1517 (Driver Selected Seat Position) and SAE J826 (Devices for Use in Defining and Measuring Vehicle Seating Accommodation). These standards were developed based on the U.S Army population (Gordon et.al.1989).

However, caution is necessary when utilising such standards as guidelines for vehicle package designs. Since the SAE standards are based on data collected in 1960's, there may have been changes to anthropometry of the population. Furthermore, according to Scott A Ziaolex PK .et al (2004), Standards based on a database of North American population could not be directly applicable to Asian population. In fact utilising a region specific database for other world regions would generally cause problem. (Nag PK .et al (2004).

Thus, the objective of this research is to compare the existing SAE Anthropometry data with a collection of anthropometric measurements based on the Malaysian population. The comparison of body segments in various vehicle design package configurations would also be analysed.

\section{Methodology}

The anthropometric measurements were adapted from three standards which were SAE J833 Human Physical Dimension, ISO 3411: 2007 Earth Moving-Physical Dimension and CATIA V5 Human Builder Population. Based on these standards, 105 parameters were identified and selected to build the human manikin in CATIA Human Modelling software. The 105 anthropometric measurements selected in this study is shown in which 23 measurements are discussed in this study. The anthropometric measurements follows the definition as prescribed by . Gordon et. al (1989).

A random sampling of 210 human subjects was chosen and their anthropometric measurements taken using manual measurement methods as described in the ISO standard. The measurements comprised of both standing and sitting anthropometric dimensions. The number of sample was determined based on convenience sampling. The subjects consisted of 105 males and 105 females with an age range of 17 years to 60 years old. Although the majority of the subjects were residing in the Lembah Pantai area, many were originally from different parts of the country. Due to this variability, the data collected is assumed to be representative of the Malaysian population. From the 105 measurements, 23 anthropometrics dimensions consisting of 11 standing measurements and 12 sitting measurements were selected for comparison with other anthropometric databases. Comparison was made with the SAE J833 database for both male and female anthropometric data as listed in SAE Standard Human Physical Dimension table (SAE J833) based on $5^{\text {th }}$ Female, $50^{\text {th }}$ Male and $95^{\text {th }}$ Male percentiles. The SAE J833 were established based on the data of United States population (SAE J833, 1989). The body ratio of the anthropometric measurements and stature were also calculated for all 23 selected anthropometric measurements. 


\section{Results and Discussion}

Table 1 shows the comparison of the selected standing measurements, as depicted in Figure 1, between the collected data and those of the SAEJ833. Whereas Table 2 compares the sitting measurements, as depicted in Figure 2, between the two databases. The comparison of the data in both Table 1 and Table 2 shows significant differences in all of the anthropometric measurements. However, the ratios of anthropometric measurement-to-stature for almost all of the selected measurements are consistent when compared to the SAE J833 database.

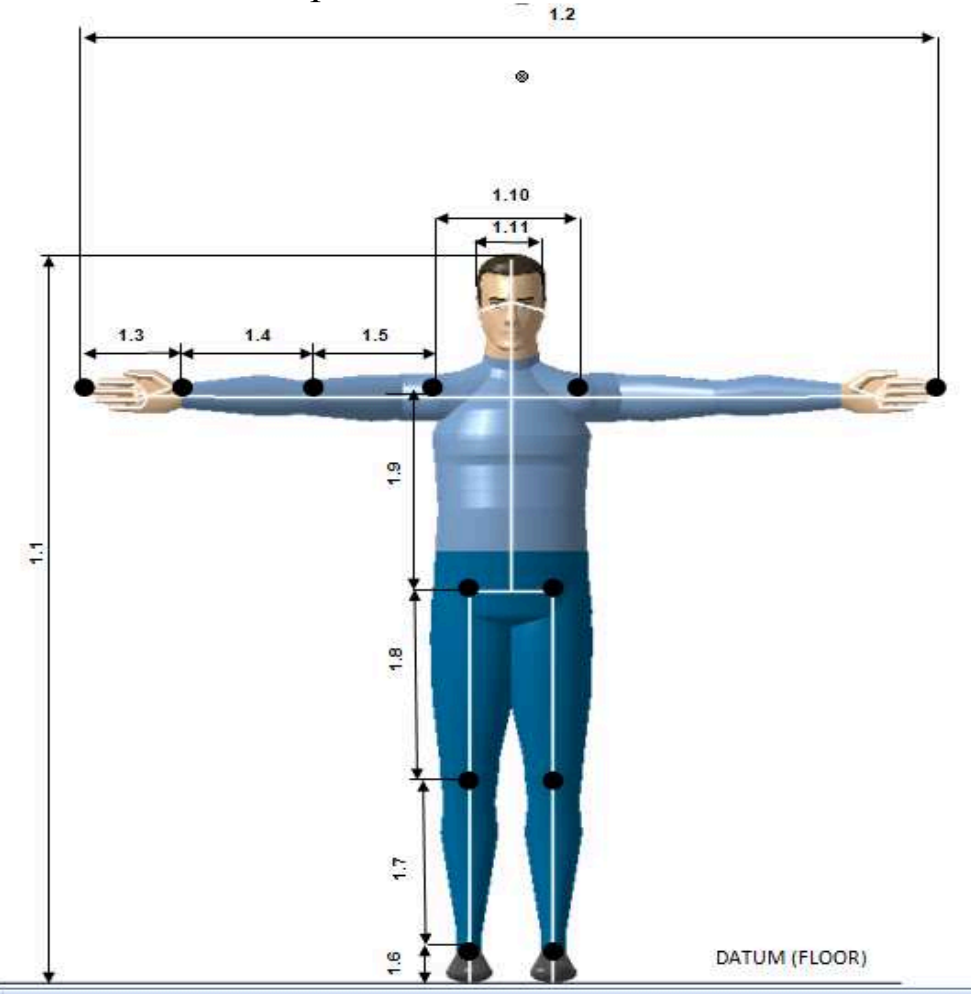

Figure 1: Standing Posture Anthropometric Measurements

Table 1: Malaysia and SAE J833 - Standing Stature

\begin{tabular}{|c|c|c|c|c|c|c|c|c|c|c|c|c|c|}
\hline \multirow[b]{2}{*}{ No. } & \multirow[b]{2}{*}{ Body segment } & \multicolumn{6}{|c|}{ Malaysia (2013) } & \multicolumn{6}{|c|}{ SAE J833: 1989} \\
\hline & & $\begin{array}{c}95 \% \\
\text { tile } \\
\text { Male } \\
\end{array}$ & Ratio & $\begin{array}{c}50 \% \\
\text { tile } \\
\text { Male } \\
\end{array}$ & Ratio & $\begin{array}{l}5 \% \text { tile } \\
\text { Female }\end{array}$ & Ratio & $\begin{array}{c}95 \% \\
\text { tile } \\
\text { Male } \\
\end{array}$ & Ratio & $\begin{array}{c}50 \% \\
\text { tile } \\
\text { Male } \\
\end{array}$ & Ratio & $\begin{array}{l}5 \% \text { tile } \\
\text { Female }\end{array}$ & Ratio \\
\hline 1.1 & Stature & 1771 & & 1671 & & 1582 & & 1854 & & 1689 & & 1524 & \\
\hline 1.2 & Arm span & 1834 & 1.03 & 1721 & 1.03 & 1622 & 1.02 & 1920 & 1.03 & 1742 & 1.03 & 1564 & 1.02 \\
\hline 1.3 & Hand length & 201 & 0.11 & 188 & 0.11 & 171 & 0.11 & 205 & 0.11 & 185 & 0.11 & 165 & 0.11 \\
\hline 1.4 & Forearm length & 292 & 0.16 & 260 & 0.15 & 225 & 0.14 & 267 & 0.14 & 244 & 0.14 & 221 & 0.14 \\
\hline 1.5 & Upper arm length & 340 & 0.19 & 307 & 0.18 & 268 & 0.17 & 300 & 0.16 & 275 & 0.16 & 250 & 0.16 \\
\hline 1.6 & Ankle height & 81 & 0.04 & 81 & 0.05 & 60 & 0.04 & 94 & 0.05 & 86 & 0.05 & 78 & 0.05 \\
\hline 1.7 & Knee height & 430 & 0.24 & 381 & 0.23 & 360 & 0.22 & 445 & 0.24 & 398 & 0.23 & 351 & 0.23 \\
\hline 1.8 & Thigh height & 440 & 0.25 & 415 & 0.23 & 386 & 0.22 & 452 & 0.24 & 407 & 0.24 & 362 & 0.23 \\
\hline 1.9 & Trunk length & 488 & 0.27 & 477 & 0.28 & 484 & 0.28 & 480 & 0.26 & 442 & 0.26 & 404 & 0.26 \\
\hline 1.10 & Shoulder width & 472 & 0.26 & 423 & 0.25 & 373 & 0.23 & 376 & 0.2 & 334 & 0.2 & 292 & 0.18 \\
\hline 1.11 & Head width & 164 & 0.09 & 155 & 0.09 & 146 & 0.09 & 165 & 0.09 & 155 & 0.09 & 145 & 0.09 \\
\hline
\end{tabular}




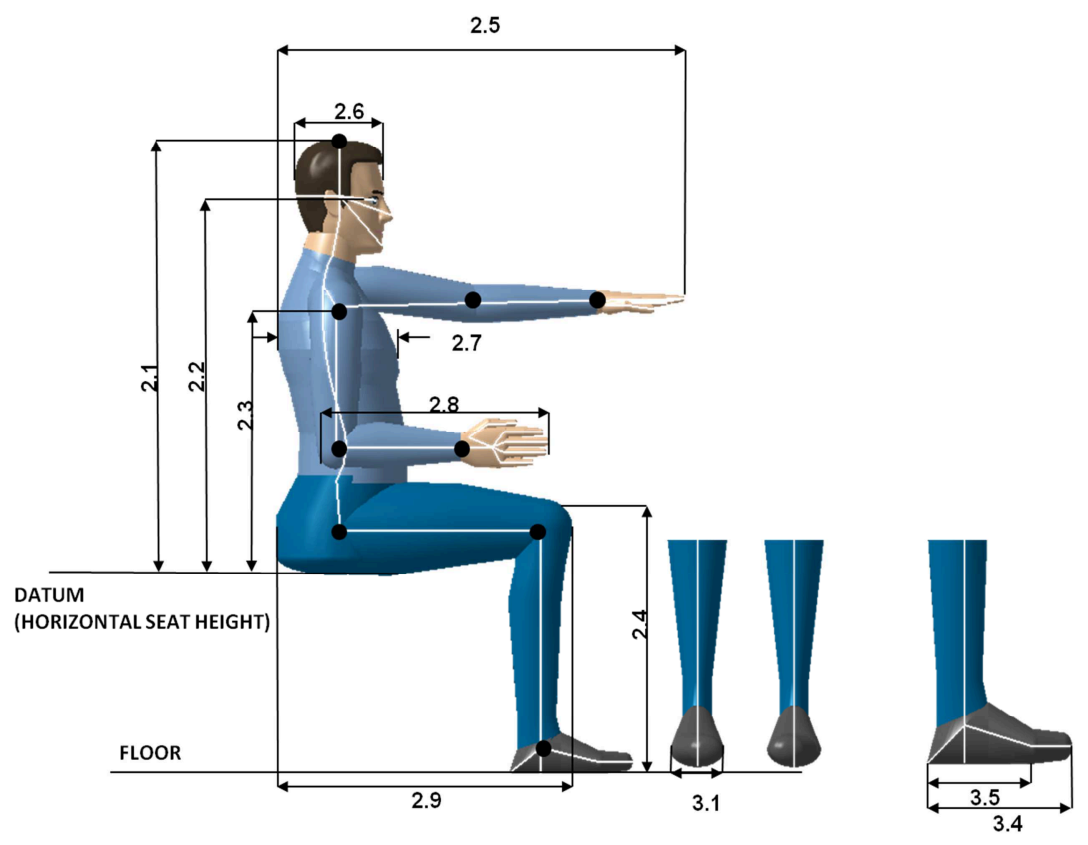

Figure 2: Sitting Posture Anthropometric Measurements

Table 2 : Malaysia and SAE J833 - Sitting Stature

\begin{tabular}{|c|c|c|c|c|c|c|c|c|c|c|c|c|c|}
\hline \multirow{2}{*}{ No. } & \multirow{2}{*}{ Body segment } & \multicolumn{6}{|c|}{ Malaysia 2013} & \multicolumn{6}{|c|}{ SAEJ833 :1989 } \\
\hline & & $\begin{array}{c}95 \% \\
\text { tile } \\
\text { Male }\end{array}$ & Ratio & $\begin{array}{c}50 \% \\
\text { tile } \\
\text { Male } \\
\end{array}$ & Ratio & $\begin{array}{l}5 \% \text { tile } \\
\text { Female }\end{array}$ & Ratio & $\begin{array}{c}95 \% \\
\text { tile } \\
\text { Male } \\
\end{array}$ & Ratio & $\begin{array}{c}50 \% \\
\text { tile } \\
\text { Male }\end{array}$ & Ratio & $\begin{array}{l}5 \% \text { tile } \\
\text { Female }\end{array}$ & Ratio \\
\hline 2.1 & Sitting height & 928 & 0.52 & 873 & 0.52 & 805 & 0.51 & 960 & 0.51 & 879 & 0.52 & 798 & 0.52 \\
\hline 2.2 & Eye height & 801 & 0.45 & 748 & 0.42 & 681 & 0.43 & 842 & 0.45 & 769 & 0.45 & 696 & 0.45 \\
\hline 2.3 & Shoulder height & 662 & 0.37 & 607 & 0.36 & 560 & 0.35 & 576 & 0.31 & 522 & 0.31 & 468 & 0.31 \\
\hline 2.4 & Knee height & 937 & 0.53 & 559 & 0.33 & 488 & 0.31 & 614 & 0.33 & 555 & 0.33 & 495 & 0.32 \\
\hline 2.5 & Thumbtip reach & 833 & 0.49 & 769 & 0.46 & 706 & 0.44 & 826 & 0.44 & 751 & 0.44 & 676 & 0.44 \\
\hline 2.6 & Head length & 195 & 0.11 & 182 & 0.11 & 170 & 0.11 & 206 & 0.11 & 195 & 0.11 & 184 & 0.12 \\
\hline 2.7 & Chest depth & 241 & 0.13 & 182 & 0.11 & 142 & 0.09 & 280 & 0.15 & 240 & 0.14 & 200 & 0.13 \\
\hline 2.8 & $\begin{array}{c}\text { Elbow to finger } \\
\text { tip }\end{array}$ & 491 & 0.28 & 455 & 0.27 & 430 & 0.27 & 510 & 0.27 & 460 & 0.27 & 410 & 0.27 \\
\hline 2.9 & $\begin{array}{c}\text { Buttock - knee } \\
\text { length }\end{array}$ & 595 & 0.33 & 540 & 0.32 & 490 & 0.31 & 648 & 0.35 & 586 & 0.34 & 524 & 0.34 \\
\hline 3.1 & Foot width & 110 & 0.06 & 98 & 0.06 & 862 & 0.05 & 104 & 0.05 & 94 & 0.05 & 84 & 0.05 \\
\hline 3.4 & Foot length & 277 & 0.15 & 251 & 0.15 & 233 & 0.14 & 284 & 0.15 & 256 & 0.15 & 250 & 0.16 \\
\hline 3.5 & $\begin{array}{l}\text { Ball of foot } \\
\text { length }\end{array}$ & 197 & 0.11 & 172 & 0.1 & 149 & 0.09 & 200 & 0.11 & 180 & 0.1 & 160 & 0.1 \\
\hline
\end{tabular}

The SAE J833 dimensions, representing the North American population, are generally higher or longer when compared to the Malaysian sample population. However, Table 1 (Standing Stature) shows that there are four body segment dimensions of the Malaysian population which are longer or higher compared to those in SAEJ833. These body segments are Forearm length, Upper arm length, Trunk length and Shoulder width. For Forearm length, the Malaysian $95 \%$ tile male size is longer by $8.7 \%$ or $25.4 \mathrm{~mm}$ and for the $50 \%$ tile male size, it is longer by $6.3 \%$ or $16.3 \mathrm{~mm}$. However, for $5 \%$ tile female, Malaysia sample population is $10 \%$ or $23 \mathrm{~mm}$ shorter as compared to 
SAE J833. For Upper arm length dimension, the Malaysian measurements are longer as compared to SAEJ 833 by $11.8 \%$ or $40.2 \mathrm{~mm}$ for $95 \%$ tile male, $10.4 \%$ or $32.1 \mathrm{~mm}$ for $50 \%$ tile male and 4.7 $\%$ or $12.5 \mathrm{~mm}$ for $5 \%$ tile female. In the case of the Trunk length dimension, it is higher by $1.6 \%$ or $8 \mathrm{~mm}$ for the Malaysian $95 \%$ tile male, $7.3 \%$ or $35 \mathrm{~mm}$ for $50 \%$ tile male and $7.9 \%$ or $25 \mathrm{~mm}$ for $5 \%$ tile female as compared to those of the SAEJ833. For Shoulder width dimension, the difference between the Malaysian data and SAE J833 is $20 \%$ or $96 \mathrm{~mm}$ for $95 \%$ tile male, $21 \%$ or $89 \mathrm{~mm}$ for $50 \%$ tile male and $21.7 \%$ or $81 \mathrm{~mm}$ for $5 \%$ tile female.

For Sitting Stature dimensions, as shown in Table 2, the SAE J833 data depicting the North American population has longer or higher body segments as compare to Malaysian population except for three body dimensions which are Shoulder height, Thumbtip reach and Foot width. The Shoulder width is higher as compared to SAE J833 by $13 \%$ or $86.4 \mathrm{~mm}$ in the $95 \%$ tile Malaysian male, $14 \%$ or $85.4 \mathrm{~mm}$ for $50 \%$ tile male. However, the $5 \%$ tile Malaysian female and SAE J833 data are equivalent. For Thumbtip reach, the $95 \%$ tile Malaysian male is slightly longer by $0.8 \%$ or $7 \mathrm{~mm}$ and for the $50 \%$ tile male is it $2.4 \%$ or $18.5 \mathrm{~mm}$ longer than its equivalent in the SAE J833. However, the $5 \%$ tile Malaysian female is shorter by $4.1 \%$ or $28 \mathrm{~mm}$. For the foot width dimension, Malaysian $95 \%$ tile male is wider by $5.4 \%$ or $6 \mathrm{~mm}$ while the $50 \%$ tile male is also wider by $4.6 \%$ or $4.6 \mathrm{~mm}$ as compared to the SAE J833. However, the $5 \%$ tile Malaysian female is shorter by $3.2 \%$ or $2.7 \mathrm{~mm}$. Figure 3 shows the comparison between SAE J833 and Malaysian population as depicted by manikins built from their respective population data.

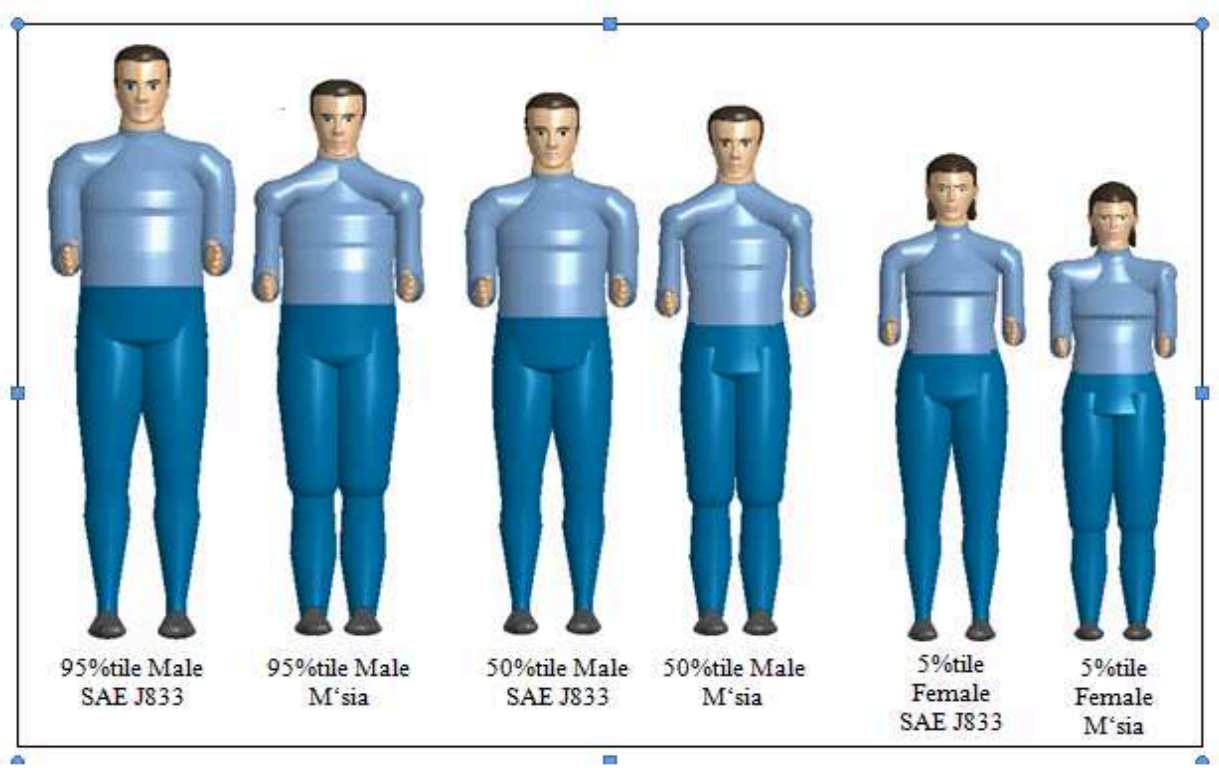

Figure 3 : Manikin model comparison SAE J833 and Malaysian population sample

In Vehicle Package design, there are several key parameters for consideration in driver cockpit space design. The Society Automotive Engineering (SAE) has recommended several guidelines which have been globally adopted by numerous automotive manufacturers (Roe, RW 1993, Society of Automotive 1998, Matthew P. Reed, et., al 1999). These parameters include the SAE J287 (Driver Reach - hand reach), SAE J941 (Driver Eyellipse - Eye location), SAE J826 (H-Point manikin), SAE J1052 (Head Position - Head Clearance), SAE J1517(Driver Selected Seat Position - seat adjustment), as shown in Figure 4. Other importance parameters such as the Shoulder room, Legroom, vision, reachability, clearances should also be considered for driver cockpit ergonomics.

The findings have shown that there are slight significant differences between the standard Human Dimension of SAE J833 (North American population) and the Malaysian population. In general, data from SAE J833 indicated longer dimensions on lower body segment which is from the 
hip to the bottom leg whereas the Malaysian population has longer dimensions on upper body segment including trunk length and arm length.

Due to these differences, there is a possibility of mismatch between vehicle package design based on SAE J833 data with those of the Malaysian population, especially on the reachability aspect to steering and pedals that influence the total body comfort posture. In addition, the hip point and eye-hip point are two key hardpoint that should be considered in determining the position and posture of the driver in driver cockpit area.

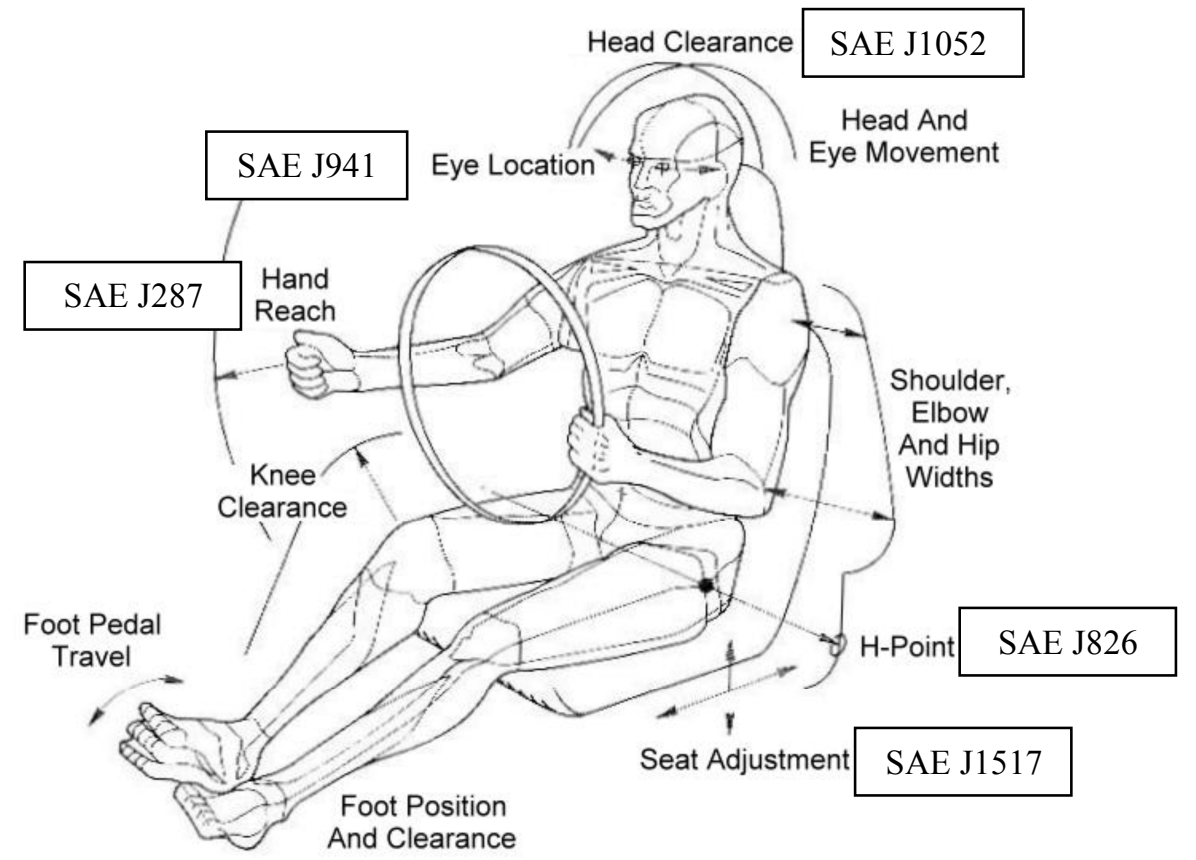

Figure 4 : SAE Recommended Standard Practise in driver cock-pit

A Pearson product-moment correlation coefficient analysis shows negative high correlations for Malaysia manikin on steering and pedals to lower body segment and high positive correlations on seating to eye height in passenger driver cockpit, as shown in Table 3.

Table 3 : Body segment correlation in passenger driver cockpit

\begin{tabular}{|c|l|c|c|}
\hline No & \multicolumn{1}{|c|}{ Parameter } & Correlation & Strength \\
\hline 1 & steering_distance \& ankle & $-.643^{* *}$ & High \\
\hline 2 & steering_height \& ankle & $-.684^{* *}$ & High \\
\hline 3 & shoe_plane \& steering_distance & $-.691^{* *}$ & High \\
\hline 4 & torso \& shoe_plane & $-.691^{* *}$ & High \\
\hline 5 & thigh \& hip & $-.711^{* *}$ & High \\
\hline 6 & shoe_plane \& steering_height & $-.748^{* *}$ & High \\
\hline 7 & torso \& shoe_plane & $-.748^{* *}$ & High \\
\hline 8 & steering_distance \& seating_height & $.716^{* *}$ & High \\
\hline 9 & steering_height \& eye_height & $.725^{* *}$ & High \\
\hline 10 & steering_distance \& eye_height & $.726^{* *}$ & High \\
\hline 11 & seating_height \& eye_height & $.794^{* *}$ & High \\
\hline 12 & steering_distance \& steering_height & $.986^{* *}$ & High \\
\hline
\end{tabular}


Therefore, in designing the driver cockpit area of a vehicle for the Malaysian population using SAE Standard design practices, specific countermeasures should be considered on the on seat, steering or pedals parameters to minimize the gaps of the body dimension to account for the variation between the Malaysian and the North American population (from which the SAE J833 is based) Those specific countermeasure may include multiple seat adjustments (fore-aft and seat height range), adjustable steering system in the form of the telescopic steering type or the possibility for adjustable pedals to accommodate different body segments.

The results from the findings of this study agrees well with previous research on driver's posture, that there is difference in postural angle between Malaysia, Korea and Caucasian (which included North American) populations due to differences in anthropometric characteristics. (Darliana et.el.,2010). Figure 5 shows the comparison of driver position in driver cockpit space for Malaysia and SAE J833 in area of reachability (steering and pedal ) and front visibility . Figure 6 shows that, due to the difference of hip point or seating position for the smallest manikin (5\%tile female Malaysia) and the biggest manikin (95\%tile male SAE J833), there is a requirement for seating adjustment (fore-aft and height) to meet the hip point distance and eye height distance as countermeasure for reachability and front vision of the driver.

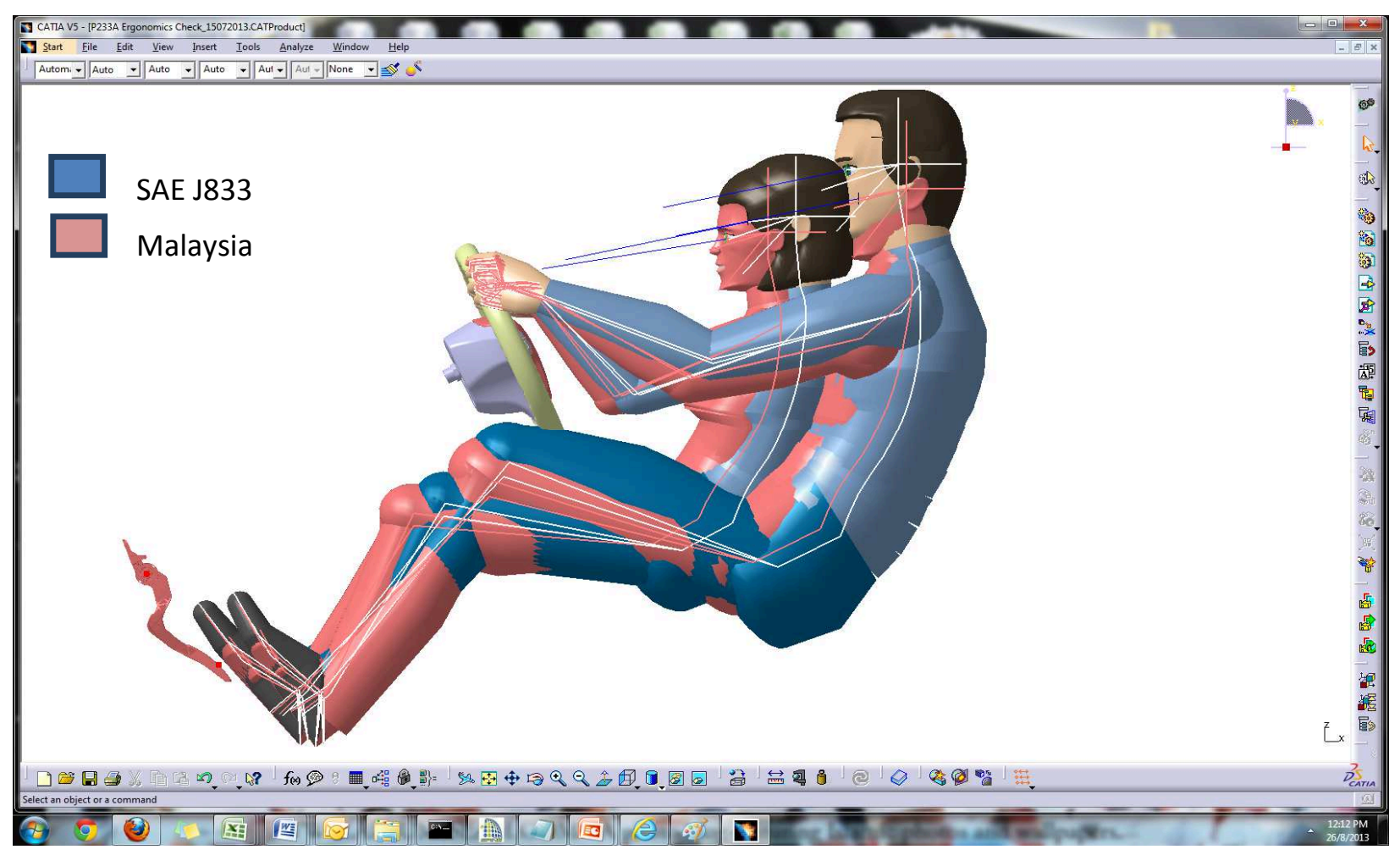

Figure 5 : Comparison of SAE J833 Manikin and Malaysia Manikin in driver position. 


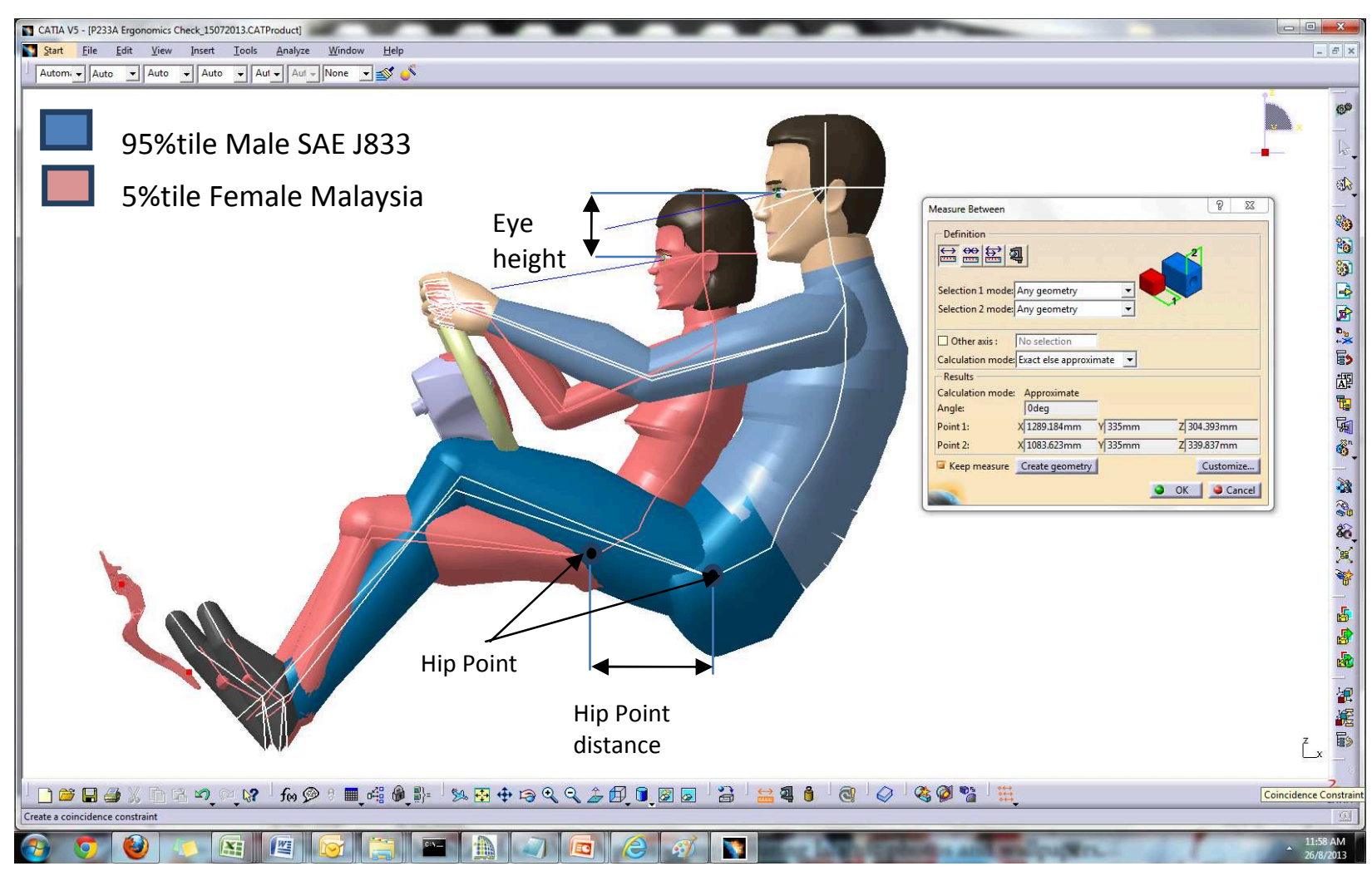

Figure 6: Manikin Comparison of $95^{\text {th }} \%$ tile SAE J833 and $5^{\text {th }} \%$ tile Female of Malaysian in driving position

\section{Conclusion}

Generally, it was shown that the Malaysian population is shorter as compared to the SAE J833 standard. The comparison has shown that the Malaysian population is shorter by $6.5 \%$ or $83 \mathrm{~mm}$ for $95 \%$ tile male, $1.1 \%$ or $18 \mathrm{~mm}$ for $50 \%$ tile male and $7.3 \%$ or $70 \mathrm{~mm}$ for $5 \%$ tile female as compared to the SAE J833 dimensions. However, there are several body segment dimensions in which the Malaysian population has slightly higher or longer dimensions as compared to SAE J833. These dimensions are the trunk height, trunk length, forearm, shoulder dimension (shoulder width and shoulder height) and slightly wider on foot width. Thus, for region specific vehicle package designs, these variations in dimensions should be considered, especially in areas related to reachability and vision. The results from this study can be utilized for the ergonomic design of vehicle cockpit especially suited for the Malaysian population.

\section{Acknowledgment}

The authors would like to thank PROTON ergonomic team and Centre of Product Design and Manufacturing $(C P D M)$, University of Malaya for their support in completing this research. 


\section{References}

[1] Roebuck, J.A (1993) Anthropometric Methods: Designing to Fit the Human Body, Human Factors and Ergonomics Society.

[2] Ebe, K., Griffin, M.J. (2001) Factors affecting static seat cushion comfort. Ergonomic.

[3] Gyi, D.E. (1996). Driver discomfort: prevalence, prediction and prevention. Loughborough University, UK.

[4] Waldemar Karwowski (2001), International Encyclopaedia of Ergonomic and Human Factors ( 3 Volume Set) L. Bandini Buti, Design of Automobile Interiors, London Taylor \& Francis.

[5] Waldemar Karwowski (2001) , International Encyclopaedia of Ergonomics and Human Factors ( 3 Volume set), M.S. Wogalther, P.G Dempsey and P.A. Hancock, Defining Ergonomics/Human Factors, London Taylor \& Francis.

[6] Waldemar Karwowski (2001) , International Encyclopaedia of Ergonomics and Human Factors ( 3 Volume set), R.E. Herron Anthropometry: Definition, Uses and Method of Measurement, London Taylor \& Francis.

[7] Brian Peacock and Waldemar Karwowski (1993), Automotive Ergonomics, London Taylor \& Francis.

[8] Grandjean,E. (1998). Fitting the Task to the Man. International Publication Service, New York.

[9] Kroemer, K., and Grandjean, E. 2003, Fitting the task to the human, 5th. edition, Taylor and Francis; Landon and New York

[10] Parkinson, M., Reed, M., Kokkolaras, M., Papalambros, P. 2007, Optimizing truck can layout for driver accommodation, Journal of Mechanical Design, 129, 1110-1117.

[11] Pheasant, S., and Haslegrave, C. 2006, Bodyspace: Anthropometry, ergonomics, and the design of work, 3rd. Edition, Taylor and Francis: London and New York.

[12] Gordon,C.C,Churchil,T.,Clausr,C.E.,Bradtmiller,B.,McConville,J.T.,Tebbetts,I.,et.al.(1989). 1989 anthropometric survey of US Army personnel : Methods and summary statistic.- Final report (NATICK/TR-891027). Natick ,MA. US Army Natick Research Development and Engineering Center.

[13] Jack Wang, John C Thornton, Mary Russell, Santiago Burastero, Steven Heymsfield and Richard N Pierson Jr - Asians have Lower Body Mass Index(BMI) but higher body fat than do whites : comparisons of anthropometric measurements. 1994 American Society for Clinical Nutrition.

[14] de Looze, M.P.,Kuijt-Evers, L.F.M., van Dieen,J.(2003) Sitting comfort and discomfort and the relationship with objective measures. Ergonomics,

[15] Cho, Y., Yoon, Y.-S. (2001) Biomechanical model of human on seat with backrest for evaluating ride quality. International Journal of Industrial Ergonomics.

[16] Roe, R.W. (1993). Occupant packaging. In Automotive Ergonomics, ed. B. Peacock and W. Karwowski, 11-42.London: Taylor and Francis.

[17] Society of Automotive Engineers (1998). Automotive Engineering Handbook. Warrendale, PA: Society of Automotive Engineers, Inc.

[18] Matthew P. Reed, Ron W. Roe, Miriam A. Manary, Carol A. C. Flannagan and Lawrence W. Schneider (1999). New Concepts in Vehicle Interior Design Using ASPECT

[19] Darliana Mohamad, Baba Md Deros, Dzuraidah Abdul Wahab, Dian Darina Indah Daruis and Ahmad Rasdan Ismail (2010), Integration of Comfort into a Driver's Car Seat Design Using Image Analysis 